\title{
Perspectivas para a Redução da Evasão em EaD a partir da Avaliação da Qualidade do Ensino Online
}

\author{
Germano O. Ribeiro ${ }^{1}$, Thomaz E. V. Silva ${ }^{2}$, Albano O. Nunes ${ }^{2}$, \\ Francisca Aparecida P. Pinto ${ }^{1}$, Francisco Herbert L. Vasconcelos ${ }^{1,2}$ \\ ${ }^{1}$ Instituto UFC Virtual - Universidade Federal do Ceará \\ Campus do Pici, B1. 901 - 60455-760 - Fortaleza - CE - Brasil \\ ${ }^{2}$ Departamento de Engenharia de Teleinformática - Universidade Federal do Ceará \\ Campus do Pici - 60455-760 - Fortaleza - CE - Brasil \\ germanoribeirol0@gmail.com, thomazveloso@virtual.ufc.br, \\ albanoliveirabrayahoo.com.br, \{aparecida.prado, herbert\}evirtual.ufc.br
}

\begin{abstract}
This paper presents the evaluation of the online educational quality in the perspective for investigating the problem of evasion in semipresential courses at a Public Institution of Higher Education. For data collection, we use an assessment tool based on the SETE methodology. The results has shonw which factors influence directly the evasion rate in a semipresential course corroborating with the literature subject, enabling pedagogical interventions in order to decrease the evasion rates of the course.
\end{abstract}

Resumo. Este trabalho apresenta a avaliação da qualidade do ensino online na perspectiva de investigar a problemática da evasão nos cursos semipresenciais de uma Instituição Pública de Ensino Superior. Para coleta das informações, utilizamos um instrumento de avaliação baseado na metodologia SETE. Os resultados apresentaram fatores que influenciam diretamente a taxa de evasão em um curso semipresencial corroborando com a literatura sobre o assunto, possibilitando intervenções pedagógicas afim de diminuir as taxas de evasão do curso.

\section{Introdução}

A Educação à Distância $(\mathrm{EaD})$ caracteriza-se pelo contato entre tutor e cursista de modo que não precisem estar unidos geográfica e temporalmente, mas apoiados por ferramentas de comunicação que potencializem os processos de ensino e aprendizagem.

Através do crescente uso da internet e das ferramentas assíncronas de comunicação a EaD vem se consolidando como metodologia de ensino tanto em nível nacional como internacional (ABRAEAD, 2012). Nesse contexto de expansão, a Universidade Federal do Ceará (UFC), por meio do Comitê Gestor Institucional de Formação Inicial e Continuada de Profissionais da Educação Básica (COMFOR)/UFC e do Instituto Universidade Virtual (Instituto UFC Virtual) vem desenvolvendo ações e cursos de formação continuada de professores em parceria com a Secretaria de Educação Continuada, Alfabetização, Diversidade e Inclusão (SECADI/MEC) na área de Educação Ambiental.

No intuito de qualificar professores das redes municipais e estadual, o Instituto UFC Virtual vem ofertando desde 2012 cursos à distância, nos quais a evasão vem se 
apresentando como um fenômeno que preocupa e chama a responsabilidade as coordenações destes cursos para intervir de forma eficaz no combate a esse problema.

Um dos desafios para superar os alarmantes índices de evasão na EaD passa pela identificação e compreensão das diferentes ações de efetividade que os gestores são chamados a intervir, pois estes através do seu poder de decisão: definem, organizam e implementam as ações necessárias para o sucesso do processo de ensino-aprendizagem.

Sendo a evasão um aspecto que envolve o ensino à distância e cada vez mais presente nas Instituições de Ensino Superior (IES) (Daudt e Behar, 2013), esta pesquisa busca identificar parâmetros que possam contribuir para minimizar os índices de desistência através de análises dos relatórios de conclusão e da correlação destes com a avaliação da percepção dos alunos ao final de duas edições do curso.

Este trabalho está organizado em 5 sessões: na sessão 2 são apresentados o conceito sobre evasão e a sua problemática no ensino em $\mathrm{EaD}$. Na sessão 3 são discutidos os aspectos metodológicos, no qual será caracterizado a amostra e a coleta dos dados. Na sessão 4 serão feitas as análises dos dados e suas interpretações. Finalmente na sessão 5, apresentamos as considerações finais e suas perspectivas futuras.

\section{Revisão da Literatura}

A partir dos dados da (ABRAEAD, 2012) nos mostram que o crescimento da modalidade semi-presencial de ensino vem se sustentando desde 2000 em vários aspectos, seja no número de universidades, vagas oferecidas, candidatos inscritos e concludentes. Outra constatação importante em meio a ampliação da quantidade, tratase do desempenho acadêmico dos alunos egresso da modalidade à distância em comparação com os alunos do sistema presencial em determinadas áreas do conhecimento.

As ofertas de cursos semi-presenciais em Instituições de Públicas de Ensino Superior, originam-se na submissão do projeto de financiamento, perpassando por fatores tais como: seleção dos conteúdos, elaboração do material didático, composição da equipe pedagógica, cronogramas das atividades, entre outros, até chegar a certificação dos cursistas. Pensada em conjunto em cada uma destas etapas, está a preocupação com a evasão.

Evasão que, segundo (Daudt e Behar, 2013), apresenta-se como um fenômeno cada vez mais presente e preocupante nas instituições de ensino superior. Daí o interesse contínuo de pesquisadores em compreender porque as pessoas abandonam os cursos e propor estratégias que combatam suas causas e minimizem seus efeitos (Sales, Barroso e Soares, 2008).

Assim como em (Favero, 2006) entende-se evasão como os cursistas que desistiram do curso em qualquer etapa dele, levando em consideração que mesmo matriculado, sequer manifestou-se em momento ou forma alguma para tutores e demais colegas. Embora sejam encontrados na literatura valores para os índices de evasão tanto em nível nacional, quanto a nível regional, estes índices não refletem fidedignamente as características da amostra do programa onde foi realizada esta pesquisa. Isto em virtude dos índices de evasão informados variarem de acordo com a região geográfica, modalidade de ensino, tipos e níveis de curso e até mesmo com a metodologia 
empregada como pode-se perceber em (Silveira, 2012) (Moreira et al, 2013) (Lacerda e Espíndola, 2013).

De acordo com os autores, os índices de evasão nos cursos online variam entre $20 \%$ e $58 \%$. No entanto, paradoxal e paralelamente a questão da diversidade dos índices de evasão, estatísticas comprovam uma expansão do Ensino à Distância, onde tal constatação vem impulsionando novas pesquisas acerca desta temática tão palpitante.

O sucesso da redução dos níveis de evasão está relacionado com estratégias de gerenciamento em aspectos tais como: pedagógico, tecnológico e acadêmico dos cursos à distância (Daudt e Behar, 2013). A gestão em EaD necessita transpor a individualidade de modelos educativos para oportunidades de se aprender em diversos locais, maneiras e a qualquer momento influência decisivamente na efetividade do ensino. Mas isso só poderá ser alcançado se o gestor além de identificar as necessidades inerentes ao curso, compreendendo também a suas variações. Já (Rotter,1966 apud Levy, 2007) utiliza-se de dois fatores: Lócus de Controle e Satisfação do estudante, já encontrados na literatura, para investigá-los como causas da evasão.

O Lócus de Controle consiste numa medida de percepções individuais sobre os resultados decorrentes de seus próprios comportamentos em relação às suas percepções sobre os resultados resultaram de ações de outra pessoa. Tem-se a percepção externa, que é fruto do acaso, falta ou destino e a percepção interna, decorrente de suas próprias ações.

Já a Satisfação do estudante está relacionada como o principal fator de decisão de abandono dos cursos à distância. (Chyung et al. 1998 apud Levy, 2007) relataram que $42 \%$ dos alunos que abandonaram o ambiente virtual, o fizeram devido a insatisfação com o ambiente de aprendizagem.

Para (Netto, Guidotti e Santos, 2012), existem diversas causas que contribuem para saída do cursista na modalidade semi-presencial, dentre elas está a não adaptação ao método. Para os autores é importante que os cursistas procurem organizar seu tempo de acordo com as demandas do curso, definindo o que é urgente e importante. Assim o aluno precisar focar-se nos pontos que o tutor elege como imprescindível para a aprendizagem do conteúdo de forma crítica e independente a fim de otimizar o tempo de permanência no Ambiente de Virtual de Aprendizagem (AVA) e não se desestimule.

No intuito de propor caminhos para o combate à evasão, (Wilges et al, 2010) propõe um modelo computacional que a partir de informações captadas no AVA que preveja possíveis candidatos a desistentes e reduza seus índices. São utilizadas informações relativas a quantidade de acesso, desempenho, participação nas atividades online. Os dados produzem um fator de risco de evasão, o qual é constantemente monitorado e avaliado pelos gestores do curso.

$\mathrm{O}$ desafio de conduzir um curso à distância no qual o sentimento de contentamento perpasse todas as suas etapas é fundamental para determinar os níveis de evasão. Por isso a maneira da gestão influenciar e passar confiança a respeitos dos aspectos pedagógicos e metodológicos aos tutores e que esta chegue aos cursistas é um dos objetivos desta pesquisa que busca investigar se esse fenômeno realmente acontece e em que proporção ele contribui com a redução da quantidade de desistentes. 


\section{Metodologia da Pesquisa}

Nesta seção, serão tratados os aspectos metodológicos que envolveram esta pesquisa, a saber: caracterização do curso e da amostra e o instrumento de coleta de dados.

\subsection{Caracterização do Curso de Aperfeiçoamento em Educação Ambiental}

Desde o ano de 2012, a UFC vem promovendo, em parceria com a SECADI, cursos de aperfeiçoamento e extensão na área de Educação Ambiental, que são destinados a capacitação de professores do ensino fundamental e médio da rede pública municipal e estadual cearense. Como vistas a aperfeiçoar a oferta destes cursos, os docentes envolvidos neles são convidados, ao final dele, a colaborar com a sua avaliação.

Tabela 1. Dados do Curso de Aperfeiçoamento em Educação Ambiental

\begin{tabular}{|l|r|r|r|}
\hline \multirow{2}{*}{ Descrição } & \multicolumn{3}{|c|}{ Ano } \\
\cline { 2 - 4 } & 2012 & 2013 & 2014 \\
\hline Concludentes & 403 & 282 & 353 \\
\hline Reprovados & 293 & 40 & 115 \\
\hline Desistentes / Nunca acessaram & 311 & 777 & 281 \\
\hline Total de Matriculados & 1007 & 1099 & 749 \\
\hline Evasão & $60 \%$ & $75 \%$ & $53 \%$ \\
\hline Número de Polos Atendidos & 21 & 12 & 11 \\
\hline
\end{tabular}

Na Tabela 1 são observados, ao longo de três anos, a frequência dos percentuais de evasão do curso de Educação Ambiental, principal aspecto desta investigação. Além disto, importante observar também as quantidades de concludentes, que respondem pelos cursistas que foram aprovados/certificados. Bem como os reprovados, os quais correspondem por aqueles que ultrapassaram metade do curso e ainda assim não conseguiram aprovação. E Desistentes / Nunca acessaram, caracterizam-se pela parcela de matriculados que não alcançou a metade do curso ou nunca interagiram de forma alguma com os tutores ou demais alunos.

\subsection{Caracterizando a Amostra}

Para caracterizar o público alvo desta pesquisa, algumas perguntas foram feitas aos cursistas que estavam concluindo o curso.

A Tabela 2 apresenta a relação de gênero entre os cursistas nos anos de 2013 e 2014. Destacamos a predominância do gênero feminino em ambos os anos.

Tabela 2. Gênero

\begin{tabular}{|rl|r|r|r|}
\hline & & Frequência & Percentual & Percentagem acumulativa \\
\hline \multirow{2}{*}{2014} & Feminino & 137 & 74,1 & 74,1 \\
& Masculino & 48 & 25,9 & 100,0 \\
& Total & 185 & 100,0 & \\
\hline \multirow{2}{*}{2013} & Feminino & 106 & 79,7 & 79,7 \\
& Masculino & 27 & 20,3 & 100,0 \\
& Total & 133 & 100,0 & \\
\hline
\end{tabular}


De acordo com a Tabela 3 , a maioria dos cursistas são jovens, com uma faixa etária de 20 a 40 anos (58,9\%). Torna-se importante que professores jovens vão em busca de formações continuadas a fim de complementar sua formação inicial.

Outro ponto importante levantado pelas questões de caracterização da amostra foi sobre a formação acadêmica dos cursistas. Na Tabela 4, podemos destacar duas inferências importantes: a grande maioria dos cursistas pertencem a área de formação de professores, com um curso de licenciatura; e dentre os cursos de licenciatura não existe uma predominância de nenhuma grande área do conhecimento, destacando a transversalidade do tema Educação Ambiental para as escolas. Tais situações ocorreram em ambos os anos, 2013 e 2014.

Tabela 3. Faixa Etária

\begin{tabular}{|c|c|c|c|c|}
\hline & & Frequência & Percentual & Percentagem acumulativa \\
\hline \multirow{6}{*}{2014} & $20-30$ anos & 49 & 26,5 & 26,5 \\
\hline & $30-40$ anos & 60 & 32,4 & 58,9 \\
\hline & $40-50$ anos & 46 & 24,9 & 83,8 \\
\hline & $50-60$ anos & 28 & 15,1 & 98,9 \\
\hline & Acima de 60 anos & 2 & 1,1 & 100,0 \\
\hline & Total & 185 & 100,0 & \\
\hline \multirow{6}{*}{2013} & $20-30$ anos & 17 & 12,8 & 12,8 \\
\hline & $30-40$ anos & 44 & 33,1 & 45,9 \\
\hline & $40-50$ anos & 56 & 42,1 & 88,0 \\
\hline & $50-60$ anos & 14 & 10,5 & 98,5 \\
\hline & Acima de 60 anos & 2 & 1,5 & 100,0 \\
\hline & Total & 133 & 100,0 & \\
\hline
\end{tabular}

Tabela 4. Formação Acadêmica

\begin{tabular}{|l|r|r|r|}
\hline & Frequência & Percentual & $\begin{array}{r}\text { Percentagem } \\
\text { acumulativa }\end{array}$ \\
\hline Bacharel Ciências da & 15 & 8,1 & 8,1 \\
Licenciado em & 58 & 31,4 & 39,5 \\
Natureza/Exatas & 1 &, 5 & 40,0 \\
Licenciado em Ciências da Saúde & 65 & 35,1 & 75,1 \\
Licenciado em Ciências Humanas & 46 & 24,9 & 100,0 \\
Licenciado em Linguagem e Códigos & 185 & 100,0 & \\
Total & 7 & 5,3 & 5,3 \\
Bacharel Ciências da & 34 & 25,6 & 30,8 \\
Licenciado em & 1 &, 8 & 31,6 \\
Natureza/Exatas & 54 & 40,6 & 72,2 \\
Licenciado em Ciências da Saúde & 37 & 27,8 & 100,0 \\
Licenciado em Ciências Humanas & 133 & 100,0 & \\
Licenciado em Linguagem e Códigos & &
\end{tabular}




\subsection{Instrumento de coleta de dados:}

A fim de captar a percepção discente acerca do conjunto de ações que compõe o curso de aperfeiçoamento em Educação Ambiental, foi elaborado um instrumento de coleta de dados a partir da metodologia SETE (do inglês Students' Evaluation the Teaching Effectiveness - SETE) (Marsh and Bailey 1993) conforme estudos prévios já realizados (Ribeiro et al, 2013).

O instrumento baseado na metodologia SETE possui 29 assertivas que buscam avaliar 8 fatores que permeiam a qualidade de cursos em EaD (Ribeiro et al, 2013). O instrumento foi disponibilizado por meio digital e para as 29 assertivas, os cursistas tinham que escolher um grau de concordância de acordo com uma escala de Likert de cinco pontos, que varia de: 1- Discordo fortemente até 5- Concordo fortemente.

\section{Resultados}

Conforme apresentado anteriormente em (Ribeiro et al, 2013), os 8 fatores provenientes do instrumento aplicado em 2013 serão apresentados na Tabela 9. Entretanto, algumas informações relevantes foram coletadas tanto no ano 2013 quanto em 2014, e merecem destaque na análise dos resultados e serão apresentados nas tabelas abaixo.

Tabela 5. Quantidade de Participação em Cursos Online

\begin{tabular}{|l|r|r|r|}
\hline & Frequência & Percentual & $\begin{array}{r}\text { Percentagem } \\
\text { acumulativa }\end{array}$ \\
\hline Esse foi o meu primeiro & 36 & 19,5 & 19,5 \\
curso & 63 & 34,1 & 53,5 \\
$1-2$ & 50 & 27,0 & 80,5 \\
$2014-4$ & 10 & 5,4 & 85,9 \\
$5-6$ & 26 & 14,1 & 100,0 \\
Acima de 6 & 185 & 100,0 & \\
Total & 28 & 21,1 & 21,1 \\
Esse foi o meu primeiro curso & 47 & 35,3 & 56,4 \\
$1-2$ & 33 & 24,8 & 81,2 \\
$3-4$ & 11 & 8,3 & 89,5 \\
$5-6$ & 14 & 10,5 & 100,0 \\
Acima de 6 & 133 & 100,0 & \\
Total & & \\
\hline
\end{tabular}

Destaca-se na Tabela 5 que 21,1\% e 19,5\%, nos anos 2013 e 2014 respectivamente, dos cursistas afirmaram que o curso de aperfeiçoamento em Educação Ambiental foi o seu primeiro curso na modalidade EaD. Tal informação torna-se importante no que diz respeito a experiência adquirida pelos cursistas que já vem passando por processos de formação utilizando a modalidade $\mathrm{EaD}$, ou seja, essas ofertas não foram o primeiro curso a serem realizados pelos cursistas. Tal experiência torna-se fundamental para sugerir um maior rigor acerca da avaliação do curso, traduzindo tais informações em informações relevantes e criteriosas. 
Embora o curso avaliado seja um curso de aperfeiçoamento e não tenha as prerrogativas legais de um curso de stricto sensu, a qualidade do curso pode ser medida pela sua dificuldade quando comparada a outros cursos em EaD. A UFC zela pela qualidade dos seus cursos livres, de extensão e de aperfeiçoamento tal qual cursos em nível de pós-graduação. A Tabela 6 mostra que a grande maioria dos cursista apontam o curso, tanto no ano 2013 quanto em 2014, com dificuldade moderada, difícil ou muito difícil quando comparado a outros cursos por eles realizados anteriormente na modalidade EaD.

Tabela 6. Dificuldade do Curso quando Comparado a Outros

\begin{tabular}{|l|r|r|r|}
\hline & Frequência & Percentual & $\begin{array}{c}\text { Percentagem } \\
\text { acumulativa }\end{array}$ \\
\hline Difícil & 23 & 12,4 & 12,4 \\
Fácil & 18 & 9,7 & 22,2 \\
Moderado & 134 & 72,4 & 94,6 \\
Muito Difícil & 8 & 4,3 & 98,9 \\
Muito Fácil & 2 & 1,1 & 100,0 \\
Total & 185 & 100,0 & 20,3 \\
Difícil & 27 & 20,3 & 27,8 \\
Fácil & 10 & 7,5 & 93,2 \\
Moderado & 87 & 65,4 & 97,7 \\
Muito Difícil & 6 & 4,5 & 100,0 \\
Muito Fácil & 3 & 2,3 & \\
Total & 133 & 100,0 & \\
\hline
\end{tabular}

Tabela 7. Atuação do Tutor Online

\begin{tabular}{|ll|r|r|r|}
\hline & Frequência & Percentual & Percentagem acumulativa \\
\hline \multirow{2}{*}{2014} & 73 & 39,5 & 39,5 \\
& Bom & 91 & 49,2 & 88,6 \\
& Ótimo & 17 & 9,2 & 97,8 \\
& Regular & 4 & 2,2 & 100,0 \\
& Ruim & 185 & 100,0 & 21,8 \\
Total & 29 & 21,8 & 85,7 \\
\hline \multirow{2}{*}{2013} & 85 & 63,9 & 89,5 \\
& Bom & 5 & 3,8 & 100,0 \\
& Regular & 14 & 10,5 & \\
& Ótimo & 133 & 100,0 & \\
& Ruim & & \\
& Total & &
\end{tabular}

$\mathrm{Na} \mathrm{EaD}$, o tutor online torna-se peça fundamental para um bom desenvolvimento do curso e consequentemente uma boa satisfação dos cursistas para com o curso. No ano de 2013 tivemos a maior faixa de frequência das respostas compreendida entre as classificações Regular e Bom (ver Tabela 7). Com base nessa informação, para a oferta do curso no ano 2014, foi inserido de uma forma temporária no curso a figura do coordenador de tutoria que tinha a função de acompanhas e orientar 
a postura dos tutores na plataforma online, tal ação gerou um resultado considerado muito significativo para os gestores do curso, no quais os tutores, em sua grande maioria, receberam a classificação Bom e Ótimo. Com base nos resultados da Tabela 7 , o coordenador de tutoria foi incorporado permanentemente em todas as atividades do curso, incluindo reuniões periódicas com os tutores e a apresentação de novas formas de intervenção pedagógica no ambiente virtual.

Tabela 8. Ritmo do Curso

\begin{tabular}{|c|c|c|c|c|}
\hline & & Frequência & Percentual & Percentagem acumulativa \\
\hline \multirow{6}{*}{2014} & Devagar & 3 & 1,6 & 1,6 \\
\hline & Ideal & 133 & 71,9 & 73,5 \\
\hline & Muito Devagar & 2 & 1,1 & 74,6 \\
\hline & Muito Rápido & 6 & 3,2 & 77,8 \\
\hline & Rápido & 41 & 22,2 & 100,0 \\
\hline & Total & 185 & 100,0 & \\
\hline \multirow{6}{*}{2013} & Devagar & 3 & 2,3 & 2,3 \\
\hline & Ideal & 97 & 72,9 & 75,2 \\
\hline & Muito Devagar & 2 & 1,5 & 76,7 \\
\hline & Muito Rápido & 3 & 2,3 & 78,9 \\
\hline & Rápido & 28 & 21,1 & 100,0 \\
\hline & Total & 133 & 100,0 & \\
\hline
\end{tabular}

Em relação a Tabela 8, o ritmo do curso foi considerado ideal para aproximadamente $72 \%$ dos cursistas nos anos 2013 e 2014. Apesar do percentual ser alto, destacamos que aproximadamente $22 \%$ dos cursistas afirmam que o curso tem um ritmo acelerado, o que pode comprometer diretamente na evasão do curso. Para que essa problemática pudesse ser solucionada, os prazos para realização das atividades foram dilatados, entretanto essa ação não surtiu efeito quanto a diminuição do ritmo do curso. Novas intervenções estão sendo pensadas para que todos possam considerar o ritmo do curso ideal frente suas possibilidades e limitações.

No ano 2013, o instrumento de avaliação (Ribeiro et al, 2013) foi aplicado nas turmas do curso, e com base nos seus resultados algumas intervenções foram realizadas afim de melhorar a qualidade do curso de aperfeiçoamento em educação ambiental e diminuir sua evasão.

Conforme apresentado na Tabela 9, todos os oito fatores foram bem avaliados, com pontuação maior do que 4. Esses resultados mostram que todos os quesitos avaliados estão satisfazendo a clientela do curso. Com base nas informações de 2013, foram realizadas intervenções afim de melhorar os indicadores avaliados. Tais ações podem ser verificadas quando compara-se os anos 2013 e 2014.

Ainda de acordo com a Tabela 9, os fatores: Atividades/Trabalho, Aprendizagem Efetiva e Interação Tutor Online/Cursista tiveram a melhor avaliação no ano 2014, mantendo o bom desempenho em relação a 2013. Isto indica que as atividades propostas procuravam inserir os conteúdos estudados a realidade dos cursistas, bem como os cursistas conseguiram aprender o conteúdo proposto pelo curso e o tutor online teve a capacidade de atrair a atenção dos alunos ao longo do curso. 
Tabela 9. Fatores da Qualidade do Ensino Online nos anos 2013 e 2014

\begin{tabular}{|l|c|c|c|c|}
\hline \multirow{2}{*}{ Fatores Avaliados } & \multicolumn{2}{|c|}{2013 (Ribeiro et al, 2013) } & \multicolumn{2}{c|}{2014} \\
\cline { 2 - 5 } & Média & Desvio Padrão & Média & Desvio Padrão \\
\hline Aprendizagem Efetiva & 4,67 & 0,05 & 4,64 & 0,06 \\
\hline Entusiasmo & 4,51 & 0,06 & 4,46 & 0,09 \\
\hline Organização Tutor Online & 4,61 & 0,12 & 4,61 & 0,08 \\
\hline Interação Tutor Online/Cursista & 4,61 & 0,06 & 4,64 & 0,06 \\
\hline Relação Tutor Presencial/Cursista & 4,44 & 0,09 & 4,42 & 0,07 \\
\hline Abrangência do Conteúdo & 4,50 & 0,04 & 4,52 & 0,08 \\
\hline Processos Avaliativos & 4,30 & 0,07 & 4,28 & 0,12 \\
\hline Atividades/Trabalhos & 4,74 & 0,02 & 4,75 & 0,02 \\
\hline
\end{tabular}

O fator Processos Avaliativos continua sendo, em 2014, o fator com o pior desempenho em relação a média. Entretanto destacamos o alto valor do seu desvio padrão $(0,12)$, ou seja, houve uma grande dispersão dos dados, garantindo que para algumas turmas o tutor foi melhor avaliado do que para outras. Embora todos os tutores online tenham recebido a mesma instrução, alguns continuaram a não deixar claro aos cursistas os seus critérios de avaliação. Atacar esse problema torna-se fundamental para diminuição de atritos entre tutores e cursistas, garantindo uma boa fluidez do curso e diminuindo sua evasão.

\section{Considerações Finais}

O nível de permanência dos cursistas nos cursos à distância tem revelado aos seus gestores e aqueles que pesquisam o tema, um constante desafio em compreendê-lo e propor soluções a fim de reduzir seus percentuais. A busca por mecanismos eficazes de combate à evasão perpassa por aspectos relacionados a administração, tecnologia e pedagógicos que facilitem a construção de uma aprendizagem cooperativa.

Esta pesquisa analisou uma série de informações, extraídas a partir de um sistemático processo avaliativo que vem se fortalecendo dentro de uma IES, que aponta para influência de três fatores na decisão do aluno em permanecer ou mesmo desistir dos cursos semipresenciais e propõe recomendações que melhorem sua qualidade e consequentemente reduzam seus índices de evasão.

Dentre as intervenções propostas, o aprimoramento qualitativo e quantitativo das atividades online, surge como um fator que apresentou uma melhora na avaliação e consequentemente na redução da evasão. Pois a dificuldade do acompanhamento das atividades está relacionada como causa de abandono dos Ambientes Virtuais de Aprendizagem.

O fator Interação Tutor Online/Cursista é outro ponto de destaque, em virtude da qualidade da interação do tutor Online ser apontada na literatura como uma das causas que influência, tanto positiva como negativamente, os índices de evasão. Nesta pesquisa, a melhora do já bem avaliado fator, reflete que além de não ter dificuldades de se comunicar com o tutor, o cursista não sente sozinho virtualmente. Esta constatação garante que os alunos estão emocionalmente vinculados ao curso (Maturana, 2002), uma vez que estabelecido o elo afetivo entre o cursista e o tutor, isto pode resultar no desejo de permanecer no Ambiente Virtual. 
A partir das análises dos aspectos que revelaram melhorias nos índices de evasão de uma edição para outra no curso de Educação Ambiental, a intervenção da figura do coordenador de tutoria, surge como possível novo elemento em relação aos fatores anteriormente discutidos. A partir desta percepção e com vistas a sua comprovação ou não, encontra-se em desenvolvimento nova investigação que possa lançar, mais uma fonte luz, ao instigante fenômeno da evasão.

Outra questão que esta pesquisa deparou-se foi o cômpito dos alunos evadidos, pois durante o processo de análises dos dados levantados, vislumbrou-se a possibilidade do conceito de evasão não está totalmente relacionado com o universo daqueles que de fato abandonam o curso, portanto interferindo nas análises das medidas de intervenção adotadas. Tal aspecto será abordado em trabalho posterior através inferências estatísticas que esclareçam essa percepção.

\section{Referências}

ABRAEAD (2012) Anuário Brasileiro Estatístico de Educação Aberta e a Distância. AbraEAD2012. ABED. Instituto Cultural e Editorial Monitor São Paulo.

Beatriz, W. et al. (2010) "Sistemas multiagentes: mapeando a evasão na educação a distância". Novas tecnologias na Educação. V.8 No 1 .

Daudt, S. I. D. e Behar, P. A. (2013) A gestão de cursos de graduação a distância e o fenômeno da evasão. Educação (Porto Alegre, impresso), v. 36, n. 3, p. 412-421.

Favero, R. V. M. (2006) Dialogar ou evadir: Eis a questão!: Um estudo sobre a permanência e a evasão na Educação a Distância, no Estado do Rio Grande do Sul. 2006. 169 f. Dissertação (Mestrado) - UFRGS, Porto Alegre.

Lacerda, F.K.D e Espíndola, R.M. (2013) Evasão na Educação a Distância: um estudo de caso. Revista EAD em Foco. Vol. 3 n $^{\circ} 1$ - Rio de Janeiro - Dezembro 2013

Levy, Y. (2007) "Comparing dropouts and persistence in e-learning courses". Computers \& Education, v.48, p.185-204.

Marsh, H. W. e Bailey, M. (1993). "Multidimensional students' evaluations of teaching effectiveness: A profile analysis". The Journal of Higher Education, 64:1-18.

Maturana, H. "Emoções e linguagem na educação e na política. Belo Horizonte: UFMG, 2002.

Moreira, P. R. (2013). Evasão escolar nos curso de graduação a distância. Anais do X Congresso Brasileiro de Ensino Superior a Distância.

Netto, C.; Guidotti, V.; Santos, P. K. (2012) "A evasão na EaD: investigando causas, propondo estratégias". In: Conferencia Latino Americana Sobre el Abandono de la Educación Superior, 2. PUCRS, Porto Alegre.

Ribeiro, G. O et al (2013). "Avaliação da Efetividade do Ensino em um Curso de Formação Continuada Semipresencial". Anais do XIX WIE.

Sales, G. L., Barroso, G. C., e Soares, J. M. (2008). "O indicador de aprendizagem learning vectors como instrumento automatizado de avaliação para suporte a aprendizagem em ead". Anais do XXVIII Congresso da SBC.

Silva, T. E. V. et al (2012). "Multivariate analysis for students' evaluation of teaching effectiveness in teleinformatics engineering". In Proc. of IEEE TALE, Hong Kong.

Silveira, C.A.B (2012). Educação a Distância e a Evasão: estudo de caso da realidade no polo UAB de Franca. Anais do SIED.

Vasconcelos, F. H. L. et al (2008). "Avaliação sóciointeracionista aplicada ao contexto da ead em cursos de graduação semi-presenciais mediado por um ambiente virtual de aprendizagem". Anais do XXVIII Congresso da SBC. 